\title{
First Steps in Growth of a Polypeptide toward $\beta$-Sheet Structure
}

\author{
Upendra Adhikari and Steve Scheiner* \\ Department of Chemistry and Biochemistry \\ Utah State University \\ Logan, UT 84322-0300 \\ *email: steve.scheiner@usu.edu \\ phone: 435-797-7419
}

\begin{abstract}
The full conformational energy surface is examined for a molecule in which a dipeptide is attached to the same spacer group as another peptide chain, so as to model the seminal steps of $\beta$ sheet formation. This surface is compared with the geometrical preferences of the isolated dipeptide so as to extract the perturbations induced by interactions with the second peptide strand. These inter-peptide interactions remove any tendency of the dipeptide to form a C5 ring structure, one of its two normally stable geometries. A C7 structure, the preferred conformation of the isolated dipeptide, remains as the global minimum in the full molecule. However, the stability of this structure is highly dependent upon inter-peptide $\mathrm{H}$-bonds with the second chain. The latter forces include not only the usual $\mathrm{NH} \cdot \cdot \mathrm{O}$ interaction, but also a pair of $\mathrm{CH} \cdot \cdot \mathrm{O} \mathrm{H}$-bonds. The secondary minimum is also of $\mathrm{C} 7$ type, and likewise depends in part upon $\mathrm{CH} \cdot \mathrm{O}^{\mathrm{O}} \mathrm{H}$-bonds for its stability. The latter interactions also play a part in the tertiary minimum. A two-strand $\beta$ sheet structure is not yet in evidence for this small model system, requiring additional peptide units to be added to each chain.
\end{abstract}

keywords: peptide-peptide interaction, $\mathrm{CH}--\mathrm{O}$ H-bond, glycyl dipeptide, rotational profile 


\section{INTRODUCTION}

The three-dimensional structure adopted by proteins rests on a variety of different structural and energetic factors. In the first place, each residue has a different dependence upon internal rotations $\varphi$ and $\psi$ around the $\mathrm{C}^{\alpha}$ atom, represented by its characteristic Ramachandran plot. There are also important interactions between non-adjacent residues that help the protein fold up into its native conformation. Probably the most well-known of the latter class are the inter-residue H-bonds. These H-bonds include not only peptide-peptide $\mathrm{NH} \cdots \mathrm{O}$ H-bonds, but also those that involve the polar sidechains of certain residues. A range of newer, and usually weaker, interactions have gained some attention in recent years, such as those involving the $\pi$ systems of aromatic systems ${ }^{1-8}$, which also contribute to protein structure. Within the context of $\mathrm{H}$-bonds, the ability of $\mathrm{CH}$ to act as proton donor has been clearly established ${ }^{9-19}$, but there is lingering discussion concerning the ability of $\mathrm{CH} \cdot \mathrm{O} \mathrm{H}$-bonds to influence the structure of proteins.

Horowitz and Trievel have recently ${ }^{20}$ summarized some of the strongest evidence to date concerning the ability of $\mathrm{CH}^{*} \cdot \mathrm{O} \mathrm{H}$-bonds to influence the structure and function of biological systems, which updates some of the earliest such compilations in this direction ${ }^{21-29}$. The combined work has catalogued such $\mathrm{H}$-bonds that involve for example the $\mathrm{C}^{\alpha} \mathrm{H}$ of the backbone within the context of $\beta$-sheets ${ }^{30-36}$. Certain residue sidechains ${ }^{37-40}$ are clearly involved as well, e.g. His ${ }^{41,42}$. Much of the earlier work has since been verified by very high-resolution crystal structures, and NMR data, to the point where $\mathrm{CH} \cdot \mathrm{O} \mathrm{H}$-bonds can be considered "highly prevalent in protein structure" 20 . These interactions serve more than a simple structural role, at times participating in enzyme catalysis $41,43,44$.

Given the complexity of proteins, and the multitude of forces that participate in their final three-dimensional structure, it is far from simple to elucidate the contribution of one specific interaction, and how the structure might differ in its absence. This problem has led to the synthesis and analysis of a number of organic systems that contain both apparent $\mathrm{CH} \cdot \cdot \mathrm{O}$ bonds and some of the elements of a full protein, but which are more conducive to detailed study of individual interactions by virtue of their smaller size ${ }^{13,15,17,18,45-49}$. The Smith group in particular has constructed molecules ${ }^{50-53}$ that contain species by which the ability of a $\mathrm{CH} \cdot \mathrm{O} \mathrm{H}$-bond to contribute to the beginnings of $\beta$-sheet structure in a protein may be tested.

A recent work in particular ${ }^{54}$ applied a hybrid combination of computations, along with a variety of experimental measurements, to demonstrate that $\mathrm{CH} \cdot \cdot \mathrm{O} \mathrm{H}$-bonds are potent enough to 
override the normal trans-planar conformational preferences of $\alpha$-fluoroamide substituents, within the context of molecules that contain the seeds of interpeptide interactions within a protein $\beta$-sheet. First by direct calculation, and also by comparison with analogous molecules without such $\mathrm{CH} \cdot \mathrm{O}$ H-bonds, the calculations estimated the strength of the interaction to lie in the neighborhood of 3-4 kcal/mol. Perhaps more to the point, both the computations and diffraction structures found geometries that would not occur were there no attractive $\mathrm{CH} \cdot \mathrm{O} \mathrm{H}-$ bond. This finding is quite consistent with prior direct calculations ${ }^{55}$ of the $\beta$-sheet which found comparable energetics of interstrand $\mathrm{NH} \cdot \cdot \mathrm{O}$ and $\mathrm{CH} \cdot \cdot \mathrm{O} \mathrm{H}$-bonds, results which were confirmed by ensuing computations ${ }^{56-59}$.

At this point, then, there appears to be compelling evidence that $\mathrm{CH} \cdot \mathrm{O} \mathrm{H}$-bonds can influence the preferred geometry of certain systems, in particular those that bear a resemblance to $\beta$-sheet structure in proteins. There are also computational assessments of the energy of such bonds, in comparison to $\mathrm{NH} \cdot \mathrm{O}$. The question remains, however, as to just how these H-bonds might influence the structure during the process during which a $\beta$-sheet is being formed. In order to address this issue, the skeleton of a two-strand $\beta$-sheet is built by tethering both strands to a spacing unit that allows appropriate flexibility. This spacing unit is chosen not only to provide the proper positioning of the two strands, but also to maximize its similarity to molecules that have been examined experimentally, which will facilitate the checking of the results once the molecule is synthesized and exposed to diffraction and spectrometric analysis.

More specifically, the molecule to be examined here is illustrated in Fig 1 where it may be noted that it is composed of two strands. The upper chain contains a pair of peptide units bracketing a $\mathrm{CH}_{2}$ group, as would occur for the Gly residue within a protein. The lower chain places a peptide unit between two $\mathrm{C}$ atoms, again simulating a very short protein chain. The two segments are connected via a phenyl ring and an ether linkage leading down to the lower chain, similar to molecules that have been previously synthesized and studied ${ }^{50-53}$. This system can be considered as the very first stage of "zipping up" a $\beta$-sheet from one end to the other. Does this pair of peptide strands begin to form a $\beta$-sheet even at this very early stage, or are more peptide units required? How does the presence of the lower peptide chain influence the structure of the upper dipeptide? Analysis can also determine whether the interstrand interactions are dominated by conventional $\mathrm{NH} \cdot \cdot \mathrm{O} \mathrm{H}$-bonds, or if there is some influence by potential $\mathrm{CH} \cdot \cdot \mathrm{O} \mathrm{H}$-bonds or perhaps some other attractive forces. 


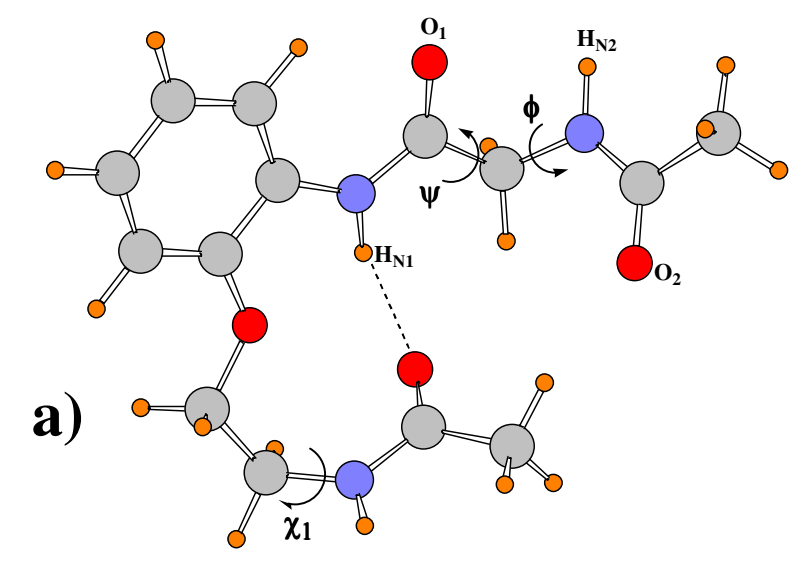

b)

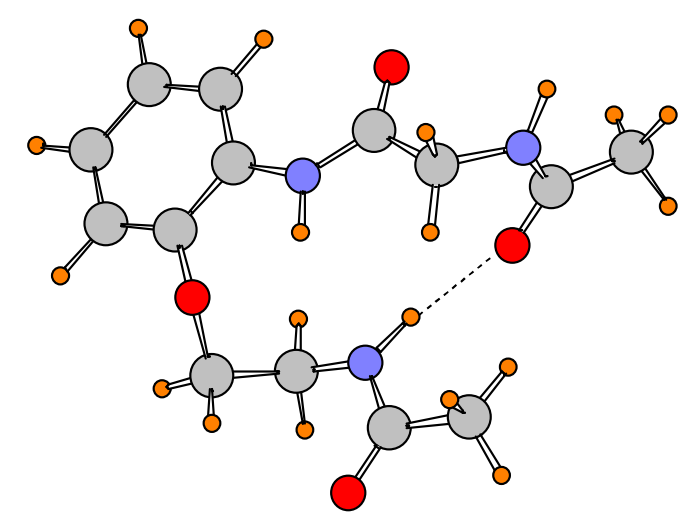

Fig 1. Structures of molecule I, with lower peptide group turned so as to present its CO group toward the upper in a, and its NH group turned in this direction in b. Important atoms are labeled, as are the dihedral angles discussed in the text.

\section{COMPUTATIONAL METHODS}

Calculations were carried out via the Gaussian 09 package ${ }^{60}$ using the M06-2X variant of density functional theory ${ }^{61}$ with a $6-31+\mathrm{G}^{* *}$ basis set. This approach was devised in part so as to better characterize intermolecular interactions of the sort being considered here, and has enjoyed good success in the past ${ }^{14,62-71}$. The DFT calculations utilized the finegrid option, which is a pruned $(75,302)$ one, specifically 75 radial shells and 302 angular points per shell, which amounts to about 7000 points for each atom. Natural bond orbital (NBO) calculations ${ }^{72,73}$ to assess intermolecular interactions were carried out using the analysis routines within the Gaussian program.

\section{RESULTS}

The most important dihedral angles of the subject molecule I are illustrated in Fig 1a, where $\varphi$ and $\psi$ have their usual meanings in the context of proteins, dealing with rotations about the 
$\mathrm{CH}_{2}$ group that lies between a pair of amide units. The orientation of the peptide unit in the lower chain is primarily controlled by the CCNC dihedral angle denoted $\chi_{1}$ in Fig 1a. A rotation around this $\mathrm{C}-\mathrm{N}$ bond can reorient the lower chain from a position where its $\mathrm{O}$ atom can form a $\mathrm{NH} \cdots \mathrm{O}$ H-bond with the first upper peptide (1a, with $\chi_{1}$ in the vicinity of $\left.-90^{\circ}\right)$ to one in which the NH group of the lower peptide interacts with the $\mathrm{C}=\mathrm{O}$ of the second upper peptide, as in Fig $1 \mathrm{~b}$, where $\chi_{1}$ is in the $+75^{\circ}$ range.

The rotational profile of molecule I is presented as a function of dihedral angle $\psi$ by the solid curve in Fig 2. This curve was generated by choosing a regular set of $\psi$ angles, with $30^{\circ}$ increments, between $0^{\circ}$ and $360^{\circ}$. For each value of $\psi$, the remainder of the molecular geometry was optimized. Since the various bond rotations can generate a number of local minima, optimizations were run for a variety of different starting values of $\varphi$ and $\chi_{1}$, as well as certain other dihedral angles. The lowest-energy minimum was taken as the global minimum for a given $\psi$ angle, and it is that energy which is plotted as the solid curve in Fig 2.

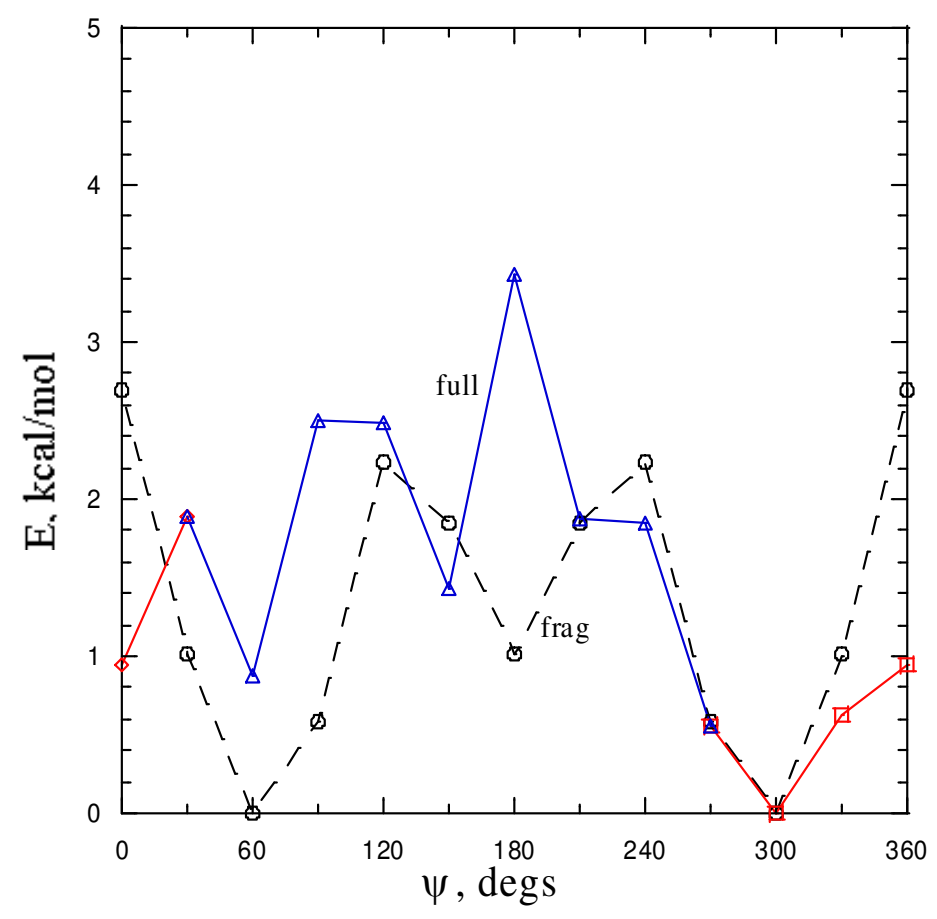


Fig 2. Energy as a function of dihedral angle $\psi$ for the simple dipeptide (broken curve) and full molecule I (solid curve). Red and blue colors indicate respectively whether the lower peptide is oriented with $\mathrm{CO}$ or NH group pointing up toward the upper dipeptide. Zero of energy is taken as the lowest value in the profile of each.

To be more specific, it was considered important to sample the full conformational space of the molecule, so as to be sure that all minima, local as well as global, were identified. Multiple minima are most likely associated with rotations around single bonds so this issue was of paramount concern. It was thus necessary to begin optimizations from a variety of starting points. First of all, peptide units were assumed to adopt their trans conformations, so geometry optimizations began with $\varphi(\mathrm{OCNH})$ dihedral angles equal to $180^{\circ}$, although this angle was subject to change as a result of geometry optimization. As stated above, separate potential energy surfaces were generated for the $\mathrm{CO}$-up and $\mathrm{NH}$-up configurations of the lower peptide, which corresponded to geometry optimizations starting with $\chi_{1}=-90^{\circ}$, and $\chi_{1}=+75^{\circ}$, although this angle was of course allowed to freely change during the optimization. Multiple orientations of the terminal methyl groups were also adopted so as to ensure obtaining the lowest possible energy, as were multiple values of the $\varphi(\mathrm{OCCN})$ and $\varphi(\mathrm{COCC})$ dihedral angles in the lower chain. Four different starting points for the $\varphi$ angle in Fig 1 were considered for each possible structure, again to be sure no minimum on the surface was overlooked. Altogether, geometry optimizations were carried out for nearly 200 different starting points, in each case holding fixed only the single parameter, $\psi$. (A full list of all starting points and optimized structures is contained in the Supporting Information.)

The solid rotational profile for the model molecule I may be compared with the dashed line in Fig 2, which represents the profile of the upper chain of I, the dipeptide $\mathrm{NH}_{2} \mathrm{COCH}_{2} \mathrm{NHCOCH}_{3}$. The most stable structure of this simple dipeptide, illustrated in Fig $3 \mathrm{a}$, occurs at $\psi=300^{\circ}$ (and its symmetrical equivalent at $\psi=60^{\circ}$ ) where its dominant feature is a C7 ring, encompassing a $\mathrm{NH} \cdots \mathrm{O} \mathrm{H}$-bond between $\mathrm{H}_{\mathrm{N} 1}$ and $\mathrm{O}_{2}$. A secondary minimum, about 1 $\mathrm{kcal} / \mathrm{mol}$ higher in energy, is present at $\psi=180^{\circ}$, which is dominated by a C $5 \mathrm{H}$-bond between $\mathrm{H}_{\mathrm{N} 2}$ and $\mathrm{O}_{1}$, as shown in Fig $3 \mathrm{~b}$. The energy barrier which the $\mathrm{C} 5 \rightarrow \mathrm{C} 7$ pathway must traverse is roughly $1.3 \mathrm{kcal} / \mathrm{mol}$, while a barrier of nearly $3 \mathrm{kcal} / \mathrm{mol}$ at $\psi=0^{\circ}$ impedes the interconversion between the two symmetric C7 structures at $\psi=60^{\circ}$ and $300^{\circ}$. 


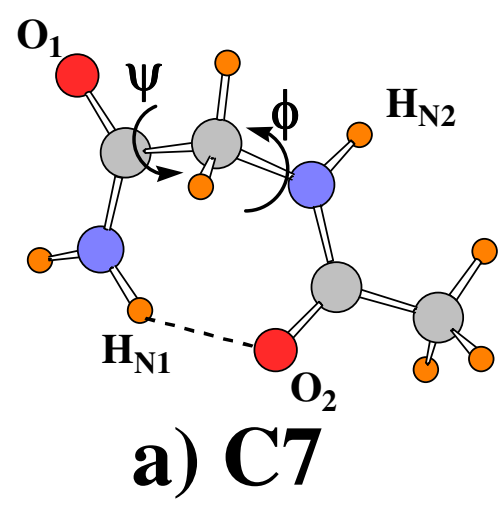

$\phi=-83, \psi=60$

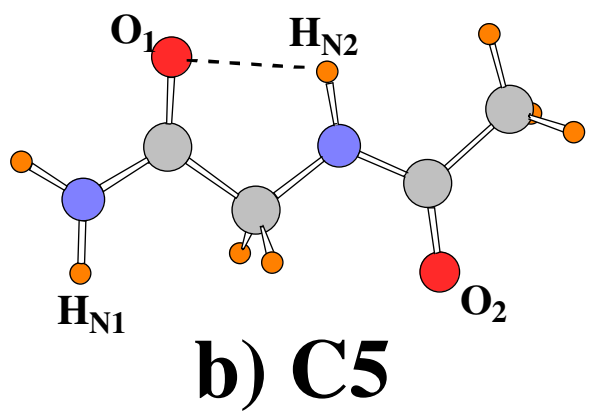

$\phi=180, \psi=180$

Fig. 3. Structures of minima on the potential energy surface of the dipeptide segment $\mathrm{NH}_{2} \mathrm{COCH}_{2} \mathrm{NHCOCH}_{3}$, indicating internal H-bond.

Comparison of the solid and dashed curves highlights some important perturbations caused by the presence of the lower peptide unit in full molecule I. The C7 minimum at $\psi=300^{\circ}$ remains intact, and retains its status as the global minimum. There is a secondary minimum at $\psi=60^{\circ}$, corresponding to the second C7 structure, but the absence of symmetry in I raises the energy of this configuration by nearly $1 \mathrm{kcal} / \mathrm{mol}$ relative to the global minimum. A more profound perturbation occurs at $\psi=180^{\circ}$ where the $\mathrm{C} 5$ minimum in the fragment is raised in energy, to the point where it becomes the highest-energy structure in the entire range. (In fact, as detailed below, the $180^{\circ}$ geometry does not contain a $\mathrm{C} 5 \mathrm{NH} \cdots \mathrm{O}$ H-bond at all.) The other secondary minimum, only slightly higher than that at $60^{\circ}$, occurs at $\psi=150^{\circ}$. This displacement from $\psi=180^{\circ}$ in the fragment to $150^{\circ}$ in the full I represents more than a slight rearrangement of the C5 fragment, encompassing an entirely new structure as described in greater detail below. Another strong perturbation is associated with $\psi=0^{\circ}$. The transition state for $\mathrm{C} 7 \rightarrow \mathrm{C} 7$ ' interconversion in the smaller fragment, represents a barrier no longer in the larger molecule. This barrier is shifted over to $\psi=30^{\circ}$, and is significantly lowered, along with substantial changes in geometry.

The reader may have noticed that the solid curve in Fig. 2 is blue for the $30^{\circ}<\psi<270^{\circ}$ range, and is red elsewhere. The two colors indicate the orientation of the lower peptide of Fig 1. Red is used to indicate values of $\psi$ for which the lowest energy geometry points the carbonyl $\mathrm{O}$ atom up toward the upper segment, as in Fig 1a, whereas conformations that orient the NH group toward the upper chain (1b) are indicated in blue. In other words, the participation in a $\mathrm{H}$ bond by the lower peptide as proton acceptor is indicated by red, and as a donor by blue. It is 
fair to wonder why the molecule should reverse its preference partway through the $\psi$ rotational profile. Why should it prefer CO up for some values of $\psi$ and $\mathrm{NH}$ up for others?

\section{Individual Rotational Profiles}

In order to answer this question, rotational profiles were generated separately for structures 1a (CO up) and 1b (NH up). The solid red curve in Fig 4b presents the energy as a function of $\psi$ for the entire molecule I, wherein the lower segment maintains its carbonyl O pointed up, even when that is not the lower energy structure. Again for reference, the rotational profile of the upper dipeptide segment by itself is illustrated by the broken curve in Fig 4a. Certain issues are particularly noticeable. For one thing, the C7 minimum at $\psi=300^{\circ}$ is intact in Fig $4 \mathrm{~b}$, but the other C7 minimum at $\psi=60^{\circ}$ is very shallow, almost entirely vanished. Indeed, the geometry of this structure does not have a C7 H-bond at all (see below). The C5 minimum at $\psi=180^{\circ}$ has in fact disappeared, shifted over by $30^{\circ}$ to $210^{\circ}$. But both the latter, and the $\psi=60^{\circ}$ minimum are much less stable than the $\psi=300^{\circ}$ conformation, by nearly $3 \mathrm{kcal} / \mathrm{mol}$. The maximum at $\psi=240^{\circ}$ of the dipeptide remains, and is in fact doubled in height, as is the barrier at $\psi=120^{\circ}$ which is shifted over toward $\psi=90^{\circ}$. 

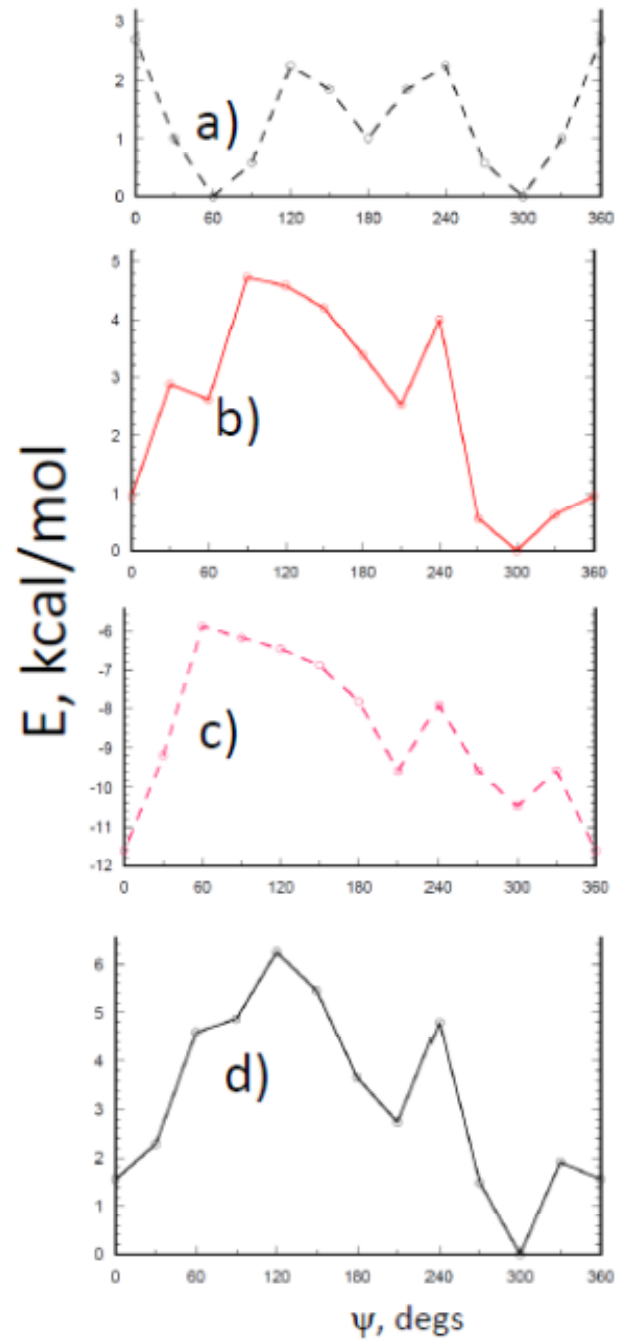

Fig 4. Energy as a function of dihedral angle $\psi$ for a) simple dipeptide and b) full molecule I with lower peptide held with $\mathrm{CO}$ group up facing the dipeptide. The interaction energy computed for the upper and lower units, in the absence of intervening phenyl and other groups, is shown in c. The sum of the latter interaction energy in $\mathrm{c}$ and the intrinsic energy of the dipeptide in a is depicted in $\mathrm{d}$. For a, b, and d, the value of zero is assigned to the lowest energy; quantities shown in c represent absolute values.

There are a number of factors that must be considered in order to understand these perturbations. First and foremost is the interaction between the upper dipeptide chain and the lower peptide unit. This interaction is dominated, but not completely so, by the $\mathrm{NH} \cdot \mathrm{O} \mathrm{H}-$ bond indicated in Fig. 1a. The interaction energy between this pair of components was estimated by taking each geometry of the full molecule in Fig. 4b, and removing the intervening groups. That is, the phenyl group was deleted, as was the connecting $\mathrm{OCH}_{2} \mathrm{CH}_{2}$, leaving only the upper 
$\mathrm{NH}_{2} \mathrm{COCH}_{2} \mathrm{NHCOCH}_{3}$ and the lower $\mathrm{CH}_{3} \mathrm{NHCOCH}_{3}$, in precisely the same geometries as they adopt in the full molecule I. The interaction energy between these two separate molecules was then computed as $\mathrm{E}_{\mathrm{int}}$.

A second factor relates to the internal geometries of the upper and lower segments. Taking the upper peptide segment as an illustration, the $\varphi$ angle in the full molecule I is not necessarily equal to, or even close to, its value when the isolated upper segment is fully optimized. For example, when $\psi=180^{\circ}$, the lowest energy structure of the upper segment $\mathrm{H}_{2} \mathrm{COCH}_{2} \mathrm{NHCOCH}_{3}$ has $\varphi=-179^{\circ}$, which enables the formation of the $\mathrm{C} 5 \mathrm{NH} \cdot \mathrm{O} \mathrm{H}$-bond. But in the full molecule I, when $\psi=180^{\circ}$, any advantage of a C5 intrapeptide H-bond is outweighed by the stability offered by interpeptide H-bonds with the lower segment, leading to an optimized $\varphi$ of $78^{\circ}$. In order to adopt the latter conformation, the upper segment must overcome an internal "distortion energy", representing the energy difference of $\varphi=78^{\circ}$, versus its natural minimum at $\varphi=-179^{\circ}$ which would include the C5 minimum. This big difference in $\varphi$ does not occur over the entire range of $\psi$, but only at a few select angles, notably $150^{\circ}<\psi<210^{\circ}$, as well as at $\psi= \pm 30^{\circ}$, so it is only here that this distortion energy must be accounted for. (There is also distortion energy within the lower segment of I, with a similar origin.)

The broken red curve of Fig $4 \mathrm{c}$ represents the total of the two aforementioned factors, the intersegment interaction energy plus the distortion energy, as a function of dihedral angle $\psi$. These two factors are most stabilizing (most negative values) in the vicinity of $\psi=0$, where there is a particularly strong interpeptide $\mathrm{NH} \cdot . \mathrm{O} \mathrm{H}$-bond, with $\mathrm{R}(\mathrm{H} \cdot \cdot \mathrm{O})=2.08 \AA$. Another value of $\psi$ for which the interpeptide interactions are highly stabilizing occurs at $210^{\circ}$, containing a short $2.07 \AA$ AH..O H-bond, augmented by a pair of fairly strong $\mathrm{CH} \cdot . \mathrm{O} \mathrm{H}$-bonds, with $\mathrm{R}(\mathrm{H} \cdot . \mathrm{O}) \sim 2.3$ $\AA$. The interpeptide attractions that occur at the third minimum in Fig. $4 \mathrm{c}, \psi=300^{\circ}$, represent a combination of $\mathrm{NH} \cdot \cdot \mathrm{O}$ and $\mathrm{CH} \cdot \cdot \mathrm{O} \mathrm{H}$-bonds, none of which are shorter than $2.3 \AA$.

When these two factors are added to the rotational profile of the upper peptide fragment in Fig 4a, one obtains the profile illustrated in Fig 4d. It is readily apparent that the overall shape of this curve is quite similar to that of the (red) actual calculated energy of the full molecule I in Fig 4b. Both curves show a global minimum at $\psi=300^{\circ}$, and a secondary minimum at $\psi=210^{\circ}$, separated by a maximum at $\psi=240^{\circ}$. In summary, then, one can account for some of the initially surprising aspects of the rotational profile of molecule I by simply adding the interpeptide 
interaction energy and the internal distortion energies to the intrinsic profile of the upper segment dipeptide molecule.

The same procedure was followed for the case where the NH group of the lower segment points up toward the upper dipeptide, and the comparable results displayed in Fig 5. The interaction energies (plus distortion energies) in Fig 5c are especially strong in the $120^{\circ}<\psi<$ $180^{\circ}$ region, which is attributed to a particularly short interpeptide $\mathrm{NH} \cdot . \mathrm{O}$ H-bond of 1.93-2.01 $\AA$. The interpeptide interaction is quite weak in the vicinity of $\psi=330^{\circ}$. Although the sum of dipeptide molecule, interpeptide and distortion energies (Fig 5d) does not superimpose quite as readily on the actual profile of the full molecule I (Fig 5b), there are strong similarities nonetheless. The region around $\psi=150^{\circ}$ is of low energy in either case, and minima are present for $\psi=60^{\circ}$ and $300^{\circ}$ (C7 regions). The peak in the energy at $\psi=330^{\circ}$ can be understood on the basis of the weak interpeptide interactions in this conformation, cf Fig 5c.
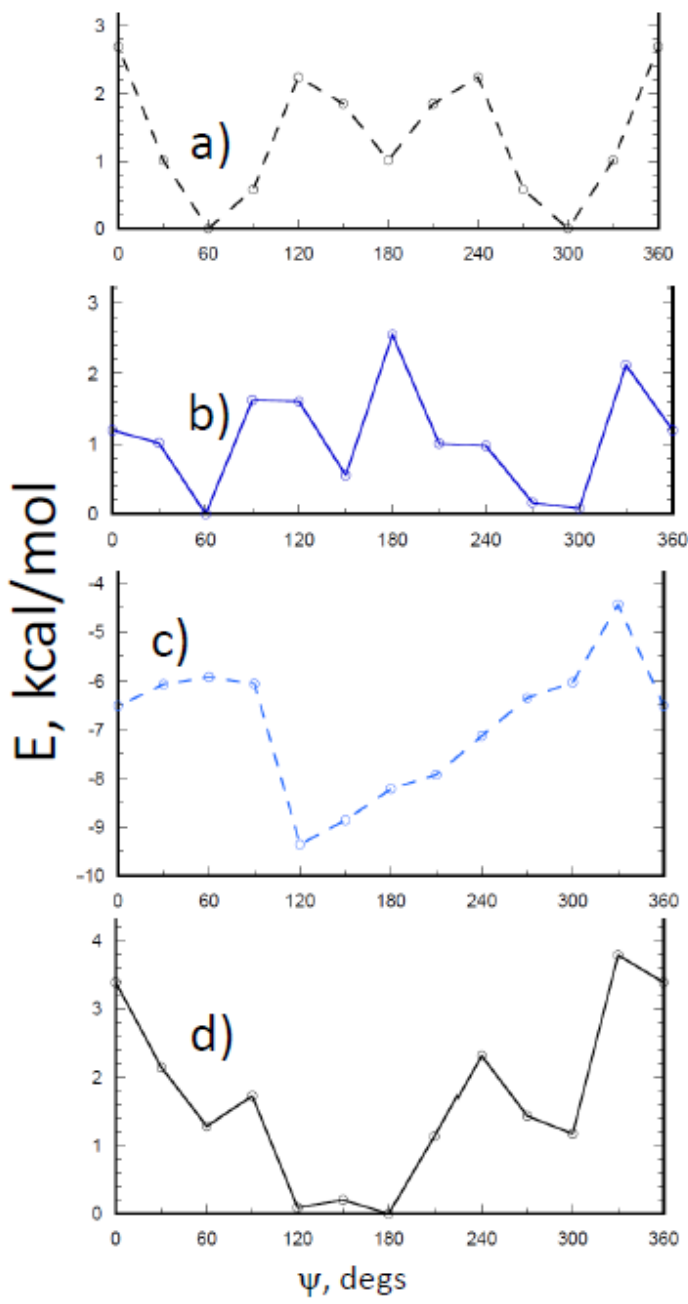
Fig 5. Energy as a function of dihedral angle $\psi$ for a) simple dipeptide and b) full molecule I with lower peptide held with $\mathrm{NH}$ group up facing the dipeptide. c shows the interaction energy between the upper and lower units, in the absence of intervening phenyl and other groups, and d represents the sum of $\mathrm{c}$ and a.

\section{Explanation}

We are now in a position to understand the basis of the full rotational profile of I illustrated in Fig 2. The lowest energy structure is plotted for the full molecule I, regardless of whether the lower segment has the $\mathrm{CO}$ or $\mathrm{NH}$ group up. The red color in Fig 2 indicates that it is the CO-up structure that is the more stable of the two at a given value of $\psi$, while the lower energy of NHup is designated by the blue color. In summary, the CO-up conformation is more stable for $270^{\circ}$ $<\psi<360^{\circ}$, while NH-up is preferred over the remainder of the $\psi$ range.

Some of the more important structures are illustrated in Fig 6. The global minimum in Fig 6a contains first of all an internal C7 NH..O H-bond of length $2.06 \AA$. One may obtain a rough estimate of the interaction energy of a H-bond such as this via the NBO E(2) perturbation energy. This quantity is equal to $6.83 \mathrm{kcal} / \mathrm{mol}$ for the $\mathrm{O}_{\mathrm{lp}} \rightarrow \sigma^{*}(\mathrm{NH})$ charge transfer, and is supplemented by a $\pi(\mathrm{CO}) \rightarrow \sigma^{*}(\mathrm{NH})$ contribution of $3.19 \mathrm{kcal} / \mathrm{mol}$. Importantly, there is a very substantial interpeptide interaction energy for this structure of $10.47 \mathrm{kcal} / \mathrm{mol}$. A chief contributor to this force is a pair of $\mathrm{CH} \cdot . \mathrm{O}$ H-bonds, of lengths 2.42 and $2.48 \AA$, with respective NBO measures of attraction of E(2) 1.95 and $1.87 \mathrm{kcal} / \mathrm{mol}$. The interpeptide $\mathrm{NH} \cdot \mathrm{O} \mathrm{H}-\mathrm{bond}$ would appear to be somewhat weaker. Even though $\mathrm{R}(\mathrm{H} \cdot \mathrm{O})$ is fairly short at $2.33 \AA$, the H-bond is far from linear, with $\theta(\mathrm{NH} \cdot \mathrm{O})=113^{\circ}$, and with $\mathrm{E}(2)$ of only $1.57 \mathrm{kcal} / \mathrm{mol}$. It is worth comparing this global minimum with the other structure with $\psi=300^{\circ}$ and a $\mathrm{C} 7$ internal $\mathrm{H}$-bond, that with $\mathrm{NH}$ up instead of $\mathrm{CO}$. Even though this conformation contains a strong interpeptide $\mathrm{NH} \cdot \mathrm{O}$ H-bond, with $\mathrm{R}(\mathrm{H} \cdot \mathrm{O}) 2.01 \AA$, and $\mathrm{E}(2)=12.52 \mathrm{kcal} / \mathrm{mol}$, it lies $1.0 \mathrm{kcal} / \mathrm{mol}$ higher in energy than the global minimum in Fig 6a. One might thus attribute the greater stability of the CO-up structure to its $\mathrm{CH} \cdot . \mathrm{O} \mathrm{H}$-bonds. 


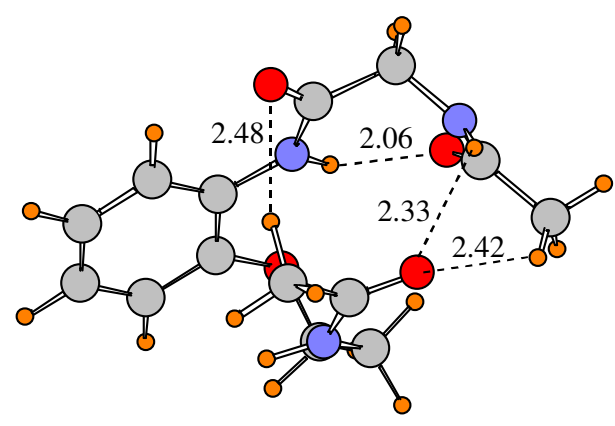

a) $\psi=300$

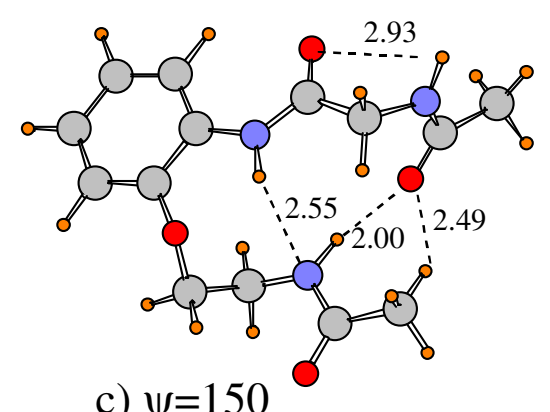

c) $\psi=150$
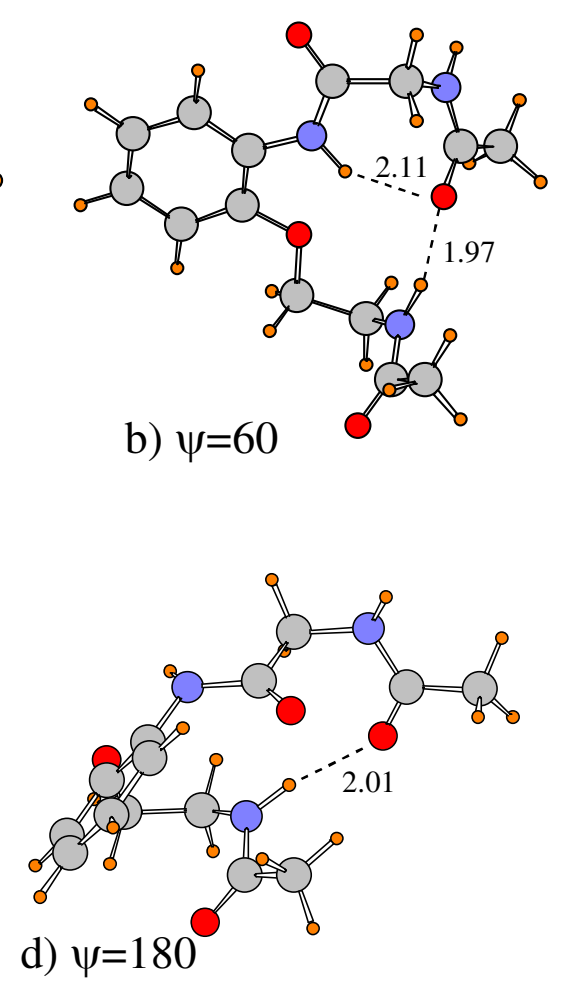

Fig. 6 Structures of selected geometries of molecule I. Selected interatomic distances are in $\AA$.

Another revealing point of comparison arises from the structure in Fig $6 \mathrm{~b}$ with $\psi=60^{\circ}$, also containing an intrapeptide $\mathrm{C} 7 \mathrm{H}$-bond, and representing a second minimum in the full rotational profile. This conformation includes a single interpeptide $\mathrm{NH} \cdot \cdot \mathrm{O}$ H-bond, and a rather strong one at that, with $\mathrm{R}(\mathrm{H} \cdot \mathrm{O})=1.97 \AA$ and $\mathrm{E}(2)=13.74 \mathrm{kcal} / \mathrm{mol}$. But again, this single $\mathrm{NH} \cdot . \mathrm{O} \mathrm{H}-$-bond results in a structure that is higher in energy that that in Fig 6a which contains two $\mathrm{CH} \cdot . \mathrm{O} \mathrm{H}-$ bonds, again by $1 \mathrm{kcal} / \mathrm{mol}$. One may conclude that the pair of strong $\mathrm{CH} \cdot \cdot \mathrm{O} \mathrm{H}$-bonds in this molecule can compete effectively even with a strong $\mathrm{NH} \cdot . \mathrm{O} \mathrm{H}-b o n d$.

The other minimum in the rotational profile of I occurs at $\psi=150^{\circ}$. Like the $180^{\circ}$ minimum in the small dipeptide profile, this structure in Fig 6c contains what might appear at first sight to be an intrapeptide $\mathrm{C} 5 \mathrm{NH} \cdot . \mathrm{O}$ H-bond. However, with $\mathrm{R}(\mathrm{H} \cdot \mathrm{O})$ fairly long at $2.93 \AA$, such a bond would be quite weak, which is confirmed by an $\mathrm{E}(2)$ of less than $0.5 \mathrm{kcal} / \mathrm{mol}$. It might thus be misleading to characterize this minimum as a mere perturbation of the original C5 minimum in the dipeptide. Its stability is based instead on purely interpeptide interactions, primarily a $\mathrm{NH} \cdot \cdot \mathrm{O}$ H-bond of length $2.00 \AA$ and with $\mathrm{E}(2)=13.62 \mathrm{kcal} / \mathrm{mol}$. The next most important interaction would appear to be a H-bond connecting the $\mathrm{NH}$ donor of the upper dipeptide with the $\mathrm{N}$ atom of 
the lower. With $\mathrm{R}(\mathrm{NH} \cdot \mathrm{N})=2.55 \AA$ and $\mathrm{E}(2)=2.13 \mathrm{kcal} / \mathrm{mol}$, this bond represents a significant contribution. Finally, there is a $\mathrm{CH} \cdot \cdot \mathrm{O}$ H-bond, with $\mathrm{R}(\mathrm{H} \cdot \cdot \mathrm{O})=2.49 \AA$ and $\mathrm{E}(2)=0.92 \mathrm{kcal} / \mathrm{mol}$. It should be noted as well that, in order to adopt a configuration amenable to this interpeptide attraction, the $\varphi$ angle of the upper dipeptide in $6 \mathrm{c}$ must change from the $-170^{\circ}$ in the small dipeptide molecule to $-65^{\circ}$ in the full molecule I, which encompasses an internal distortion energy of $0.8 \mathrm{kcal} / \mathrm{mol}$. The strain energy in the lower segment is even larger, $1.4 \mathrm{kcal} / \mathrm{mol}$. In other words, the interpeptide attraction is strong enough to force a total distortion energy of 2.2 $\mathrm{kcal} / \mathrm{mol}$, and yet remain a minimum in the rotational profile.

It might be noted that whereas $\psi=180^{\circ}$ represents a minimum in the profile of the small dipeptide segment, that same dihedral angle corresponds to the highest energy structure in the entire rotational profile of the full molecule I. It is immediately clear that this conformation in Fig 6d does not include anything resembling a $\mathrm{C} 5 \mathrm{NH} \cdot \cdot \mathrm{O} \mathrm{H}$-bond. Instead, the most significant contribution to its stability resides in an interpeptide $\mathrm{NH} \cdot . \mathrm{O}$ H-bond, with length $2.01 \AA$ and $\mathrm{E}(2)=12.94 \mathrm{kcal} / \mathrm{mol}$. Part of the instability of this structure arises from the distortion energy imposed on its upper dipeptide segment of $2.3 \mathrm{kcal} / \mathrm{mol}$ in order to achieve a conformation amenable to this $\mathrm{NH} \cdot \cdot \mathrm{O}$ H-bond. In other words, in the small dipeptide molecule $\varphi$ would be $180^{\circ}$ when $\psi=180^{\circ}$. But $\varphi$ readjusts to $68^{\circ}$ in the full molecule, costing the system $2.3 \mathrm{kcal} / \mathrm{mol}$. From a broader perspective, the $\mathrm{C} 5 \mathrm{H}$-bond is the prime contributor to the minimum in the simple dipeptide. But this intrapeptide H-bond cannot be sustained in larger molecules where it is supplanted by interpeptide attractions, and the cost of breaking the intrapeptide H-bond raises the energy of the entire system.

\section{DISCUSSION}

It is now possible to both summarize the overall effects of the presence of the lower peptide group upon the conformational profile of the upper dipeptide, and also account for these effects via fundamental principles. The preference of the dipeptide for a geometry that encompasses a $\mathrm{C} 7 \mathrm{NH} \cdot \mathrm{O} \mathrm{H}$-bond is left unaltered, with a global minimum occurring at $\psi=300^{\circ}$ in either case (and with $\varphi=83^{\circ}$ in both systems). However, in order to retain this privileged status as structure of lowest energy, under competition from other geometries with a very substantial interpeptide $\mathrm{NH} \cdot \mathrm{O} \mathrm{H}$-bond, the global minimum relies upon a pair of $\mathrm{CH} \cdot \mathrm{O} \mathrm{H}$-bonds to supplement the weaker, highly angularly distorted $\mathrm{NH} \cdot$. O interpeptide interaction. This geometry has a $\psi$ angle quite close to that of the standard $\alpha$-helix in the Ramachandran plot, that occurs at $\left(-58^{\circ},-50^{\circ}\right)$. 
However, its $\varphi$ angle of $83^{\circ}$ is significantly distant from that of the $\alpha$-helix at roughly $-58^{\circ}$. So one might conclude that the presence of the lower peptide in I is insufficient to stimulate the adoption of an $\alpha$-helical conformation in the dipeptide. This failure is not surprising since the $\alpha$ helical structure is stabilized by $\mathrm{H}$-bonds between residues further separated along its chain than are possible in a dipeptide.

The second most stable minimum of the full molecule I is also of $\mathrm{C} 7$ type. In addition to the intrapeptide $\mathrm{C} 7 \mathrm{H}$-bond, it contains a strong interpeptide $\mathrm{NH} \cdot . \mathrm{O} \mathrm{H}$-bond, with $\mathrm{R}(\mathrm{H} \cdot \cdot \mathrm{O})=1.97 \AA$, and with $\theta(\mathrm{NH} \cdot \mathrm{O})$ nearly linear at $163^{\circ}$. Nonetheless, the stability conferred by this latter interaction appears to be weaker than the $\psi=300^{\circ}$ minimum, relying upon $\mathrm{CH} \cdot \cdot \mathrm{O} \mathrm{H}$-bonds to supplement a $\mathrm{NH} \cdot \mathrm{O}$ H-bond of only moderate strength.

As mentioned above, the presence of the lower peptide eliminates the $\mathrm{C} 5$ minimum of the simple dipeptide which occurs at $(\varphi, \psi)=\left(180^{\circ}, 180^{\circ}\right)$. Instead, the tertiary minimum of the full molecule I shifts $\psi$ down to $150^{\circ}$, and changes $\varphi$ to $-65^{\circ}$. While the $\psi$ angle is beginning to approach its value of $112^{\circ} / 135^{\circ}$ in the parallel/anti-parallel $\beta$-sheets, respectively, the $\varphi$ angle of $-65^{\circ}$ is far removed from the corresponding values of $-120^{\circ}$ and $-140^{\circ}$ in the $\beta$-sheet. Molecule I is therefore too small a model to force the appearance of an incipient $\beta$-sheet, although the $\psi=150^{\circ}$ minimum does include the interpeptide $\mathrm{NH} \cdot \cdot \mathrm{O}$ and $\mathrm{CH} \cdot \cdot \mathrm{O} \mathrm{H}$-bonds that are a trademark of the $\beta$-sheet.

In summary, then, the presence of the lower peptide group leaves largely intact the preference of a dipeptide to adopt a C7-type geometry, even though its stability depends in large measure on interactions between the upper and lower peptide chains. The C5 structure of the dipeptide, on the other hand, is a fragile one, in that it vanishes upon placement of the lower peptide group in the vicinity of the upper dipeptide. The presence of the lower peptide group induces the formation of a tertiary minimum in the upper dipeptide, at $\psi=150^{\circ}$, whose stability rests upon both weak $\mathrm{CH} \cdot \cdot \mathrm{O}$ and $\mathrm{NH} \cdot \cdot \mathrm{N}$ H-bonds to supplement a much stronger $\mathrm{NH} \cdots \mathrm{O}$ interaction.

Of course, a full $\beta$-sheet contains many more peptide units than does the model system considered here, which includes a pair of peptides on the upper strand and only a single peptide on the lower. And the structure of the connecting unit, with its phenyl ring and ether linkage, does not provide the full range of flexibility that would accrue to a protein molecule's longer, 
multistrand $\beta$-sheet. These factors might limit the ability of the model molecule to engage in a structure that is a truly accurate reproduction of a $\beta$-sheet.

Despite the small size, however, one can see abundantly clear evidence that the peptide units in the two strands do indeed have a strong influence upon the conformational preferences of one another. These effects are obvious first in the very different character of the rotational profiles of the fragment and full molecule, displayed by the broken and solid curves, respectively, in Fig 2. For example, it is this interstrand interaction that eliminates the C5 minimum present in the structure of a single strand, turning this sort of structure from a minimum to a maximum in the potential energy surface. And this mutual effect is unambiguously traced to the H-bonds that occur between the two strands, a necessary ingredient in the ultimate $\beta$-sheet formation in a protein. The evidence for this $\mathrm{H}$-bond participation arises not only from NBO orbital interaction energies, but also from direct calculation of the interaction energies between the two segments. At this early stage of protein structure nucleation, the results further indicate that $\mathrm{CH} \cdot \mathrm{O} \mathrm{H}$-bonds play a very important role, secondary only to the stronger $\mathrm{NH} \cdot \mathrm{O}$ bonds that are normally considered to be completely dominant.

Lastly with respect to the accuracy that might be expected for the theoretical method applied here, the M06-2X approach was chosen in part for its design and superior performance in dealing with noncovalent interactions. Nonetheless, the data are not perfect. A recent study ${ }^{74}$ found that the M06 family of functionals handle H-bonded systems rather well, reproducing much of the dispersive attractions needed for long range interactions, but there is a lingering error in the range of perhaps $0.5-1.0 \mathrm{kcal}$ in applications to H-bonded systems. DFT methods such as M06$2 \mathrm{X}$ also apply integration grid quadrature methods which can be subject to certain errors as well. However, a recent test ${ }^{75}$ found the error to be expected from the grid applied here ought to be well under $0.1 \mathrm{kcal} / \mathrm{mol}$.

In order to insure the validity of the M06-2X data, two other functionals were used to compare the energies of some of the most important structures. The geometries illustrated in Fig 6 for $\psi=300,60$, and 150 all correspond to minima in the rotational profiles (see Fig 2). The energies of these structures were computed using two other functionals B97D ${ }^{76}$ and $\omega_{B} 97 \mathrm{XD}^{77}$, both of which were designed in part to describe long-range dispersion effects. And indeed there is evidence ${ }^{78}$ that the latter approach, as well as M06-2X, provide superior reproduction of the so-called gold standard for noncovalent forces, $\operatorname{CCSD}(\mathrm{T})$. Although there were of course some 
changes in the quantitative energy differences, both methods confirmed the energetic ordering obtained by M06-2X. As a further check on the M06-2X method, ab initio MP2 calculations were carried out on the same three important configurations, and again there was no change in their energetic ordering. This similarity is not surprising as MP2 and the M0n-2X series have been found ${ }^{79}$ to correlate quite well with one another in complexes containing comparable sorts of interactions

\section{ACKNOWLEDGMENTS}

Thanks to Prof. Martin Smith and Dr. Russell Driver of Oxford University for developing and suggesting model molecules of this sort. Computer, storage and other resources from the Division of Research Computing in the Office of Research and Graduate Studies at Utah State University are gratefully acknowledged, as is financial support from the NSF, Grant CHE1026826.

Supporting Information Available:

A table of all starting structures considered, as well as the optimized angles and energies. The

full list of authors of refs 19 and 60 is also included. This information is available free of charge via the Internet at http://pubs.acs.org 


\section{REFERENCES}

(1) Takahashi, O.; Kohno, Y.; Nishio, M. Relevance of Weak Hydrogen Bonds in the Conformation of Organic Compounds and Bioconjugates: Evidence from Recent Experimental Eata and High-Level Ab Initio Mo Calculations. Chem. Rev., 2010, 110, 6049-6076.

(2) Wheeler, S. E.; McNeil, A. J.; Müller, P.; Swager, T. M.; Houk, K. N. Probing Substituent Effects in Aryl-Aryl Interactions Using Stereoselective Diels Alder Cycloadditions. J. Am. Chem. Soc., 2010, 132, 3304-3311.

(3) Nishio, M. The $\mathrm{Ch} / \Pi$ Hydrogen Bond in Chemistry. Conformation, Supramolecules, Optical Resolution and Interactions Involving Carbohydrates. Phys. Chem. Chem. Phys., 2011, 13, 13873-13900.

(4) Kumar, S.; Pande, V.; Das, A. П-Hydrogen Bonding Wins over Conventional Hydrogen Bonding Interaction: A Jet-Cooled Study of Indole...Furan Heterodimer. J. Phys. Chem. A, 2012, 116, 1368-1374.

(5) Gierszal, K. P.; Davis, J. G.; Hands, M. D.; Wilcox, D. S.; Slipchenko, L. V.; BenAmotz, D. П-Hydrogen Bonding in Liquid Water. J. Phys. Chem. Lett., 2011, 2, 29302933.

(6) Saggu, M.; Levinson, N. M.; Boxer, S. G. Experimental Quantification of Electrostatics in X-H...П Hydrogen Bonds. J. Am. Chem. Soc., 2012, 134, 18986-18997.

(7) Amicangelo, J. C.; Irwin, D. G.; Lee, C. J.; Romano, N. C.; Saxton, N. L. Experimental and Theoretical Characterization of a Lone Pair-П Complex: Water-Hexafluorobenzene. J. Phys. Chem. A, 2013, 117, 1336-1350.

(8) Sherrill, C. D. Energy Component Analysis of П Interactions. Acc. Chem. Res., 2013, 46, 1020-1028.

(9) Sutor, D. J. Evidence for the Existence of C-H'”O Hydrogen Bonds in Crystals. J. Chem. Soc., 1963, 1105-1110.

(10) Krimm, S.; Kuroiwa, K. Low Temperature Infrared Spectra of Polyglycines and C-H ... $\mathrm{O}=\mathrm{C}$ Hydrogen Bonding in Polyglycine Ii. Biopolymers, 1968, 6, 401-407.

(11) Taylor, R.; Kennard, O. Crystallographic Evidence for the Existence of C-H ${ }^{\cdots \cdots} \mathrm{O}, \mathrm{C}-\mathrm{H}^{\cdots \cdots} \mathrm{N}$, and C-H”'Cl Hydrogen Bonds. J. Am. Chem. Soc., 1982, 104, 5063-5070.

(12) Schwalbe, C. H. June Sutor and the C-H...O Hydrogen Bonding Controversy. Cryst. Rev., 2012, 18, 191-206.

(13) You, L.-Y.; Chen, S.-G.; Zhao, X.; Liu, Y.; Lan, W.-X.; Zhang, Y.; Lu, H.-J.; Cao, C.-Y.; Li, Z.-T. C-H”'O Hydrogen Bonding Induced Triazole Foldamers: Efficient Halogen Bonding Receptors for Organohalogens. Angew. Chem. Int. Ed., 2012, 51, 1657-1661.

(14) Lee, K.-M.; Chen, J. C. C.; Chen, H.-Y.; Lin, I. J. B. A Triple Helical Structure Supported Solely by C-H“'O Hydrogen Bonding. Chem. Commun., 2012, 48, 1242-1244.

(15) Vibhute, A. M.; Gonnade, R. G.; Swathi, R. S.; Sureshan, K. M. Strength from Weakness: Opportunistic Ch"O Hydrogen Bonds Differentially Dictate the Conformational Fate in Solid and Solution States. Chem. Commun., 2012, 48, 717-719.

(16) Sigalov, M. V.; Doronina, E. P.; Sidorkin, V. F. C $\mathrm{ar}_{\mathrm{ar}}-\mathrm{H} \cdots \mathrm{O}$ Hydrogen Bonds in Substituted Isobenzofuranone Derivatives: Geometric, Topological, and Nmr Characterization. J. Phys. Chem. A, 2012, 116, 7718-7725.

(17) Lippert, K. M.; Hof, K.; Gerbig, D.; Ley, D.; Hausmann, H.; Guenther, S.; Schreiner, P. R. Hydrogen-Bonding Thiourea Organocatalysts: The Privileged 3,5-

Bis(Trifluoromethyl)Phenyl Group. Eur. J. Org. Chem., 2012, 2012, 5919-5927. 
(18) Huang, Z.; Chen, Z.; Lim, L. H.; Quang, G. C. P.; Hirao, H.; Zhou, J. S. Weak Arene C$\mathrm{H}^{\cdots} \mathrm{O}$ Hydrogen Bonding in Palladium-Catalyzed Arylation and Vinylation of Lactones. Angew. Chem. Int. Ed., 2013, 52, 5807-5812.

(19) Gao, X.; Liu, Y.; Li, H.; Bian, J.; Zhao, Y.; Cao, Y.; Mao, Y.; Li, X.; Xu, Y.; Ozaki, Y.; et al. Cooperative Hydrogen Bonding System with a C-H'”O Hydrogen Bond in Ofloxacin. J. Mol. Struct., 2013, 1040, 122-128.

(20) Horowitz, S.; Trievel, R. C. Carbon-Oxygen Hydrogen Bonding in Biological Structure and Function. J. Biol. Chem., 2012, 287, 41576-41582.

(21) Huggins, M. L. The Structure of Fibrous Proteins. Chem. Rev., 1943, 32, 195-218.

(22) Krimm, S. Hydrogen Bonding of $\mathrm{C}-\mathrm{H}^{\cdots \cdots} \mathrm{O}=\mathrm{C}$ in Proteins. Science, 1967, 158, 530-531.

(23) Ramachandran, G. N.; Chandrasekharan, R. Interchain Hydrogen Bonds Via Bound Water Molecules in the Collagen Triple Helix. Biopolymers, 1968, 6, 1649-1658.

(24) Derewenda, Z. S.; Lee, L.; Derewenda, U. The Occurrence of C-H'*O Hydrogen Bonds in Proteins. J. Mol. Biol., 1995, 252, 248-262.

(25) Bella, J.; Berman, H. M. Crystallographic Evidence for $\mathrm{C}^{\alpha}-\mathrm{H}^{\cdots \cdots} \mathrm{O}=\mathrm{C}$ Hydrogen Bonds in a Collagen Triple Helix. J. Mol. Biol., 1996, 264, 734-742.

(26) Wahl, M. C.; Sundaralingam, M. C-H”'O Hydrogen Bonding in Biology. Trends Biochem. Sci., 1997, 22, 97-102.

(27) Weiss, M. S.; Brandl, M.; Sühnel, J.; Pal, D.; Hilgenfeld, R. More Hydrogen Bonds for the (Structural) Biologist. Trends Biochem. Sci., 2001, 26, 521-523.

(28) Senes, A.; Ubarretxena-Belandia, I.; Engelman, D. M. The C $\alpha-H$ O Hydrogen Bond: A Determinant of Stability and Specificity in Transmembrane Helix Interactions. Proc. Nat. Acad. Sci., USA, 2001, 98, 9056-9061.

(29) Manikandan, K.; Ramakumar, S. The Occurrence of Ch...O Hydrogen Bonds in $\alpha-$ Helices and Helix Termini in Globular Proteins. Proteins Struct. Func. Genetics, 2004, 56, 768-781.

(30) Fabiola, G. F.; Krishnaswamy, S.; Nagarajan, V.; Pattabhi, V. C-H“'O Hydrogen Bonds in B-Sheets. Acta Cryst., 1997, D53, 316-320.

(31) Nagarajan, V.; Pattabhi, V.; Johnson, A.; Bobde, V.; Durani, S. Crystal Structures of Heterochiral Peptides. Part Ii. Tert-Boc-Valyl-D-Alanyl-Leucyl-Alanyl Methoxide. $J$. Peptide Res., 1997, 49, 74-79.

(32) Ridder, I. S.; Rozeboom, H. J.; Dijkstra, B. W. Haloalkane Dehalogenase from Xanthobacter Autotrophicus Gj10 Refined at $1.15 \AA$ Resolution. Acta Cryst., 1999, D55, 1273-1290.

(33) Sandalova, T.; Schneider, G.; Käck, H.; Lindqvist, Y. Structure of Dethiobiotin Synthetase at $0.97 \AA$ Resolution. Acta Cryst., 1999, D55, 610-624.

(34) Addlagatta, A.; Krzywda, S.; Czapinska, H.; Otlewski, J.; Jaskolski, M. UltrahighResolution Structure of a Bpti Mutant. Acta Cryst., 2001, D57, 649-663.

(35) Cordier, F.; Barfield, M.; Grzesiek, S. Direct Observation of $\mathrm{C}^{\alpha}-\mathrm{H}^{\alpha \ldots \mathrm{O}}=\mathrm{C}$ Hydrogen Bonds in Proteins by Interresidue ${ }^{\mathrm{H} 3} \mathrm{j}_{\mathrm{cac}}$ Scalar Couplings. J. Am. Chem. Soc., 2003, 125, $15750-15751$.

(36) Kang, B. S.; Devedjiev, Y.; Derewenda, U.; Derewenda, Z. S. The Pdz2 Domain of Syntenin at Ultra-High Resolution: Bridging the Gap between Macromolecular and Small Molecule Crystallography. J. Mol. Biol., 2004, 338, 483-493.

(37) Chakrabarti, P.; Chakrabarti, S. C-H $\cdots O$ O Hydrogen Bond Involving Proline Residues in $\alpha$ Helices. J. Mol. Biol., 1998, 284, 867-873. 
(38) Babu, M. M.; Singh, S. K.; Balaram, P. A C-H...O Hydrogen Bond Stabilized Polypeptide Chain Reversal Motif at the C Terminus of Helices in Proteins. J. Mol. Biol., 2002, 322, 871-880.

(39) Shi, Z.; Olson, C. A.; Bell, A. J.; Kallenbach, N. R. Non-Classical Helix-Stabilizing Interactions: $\mathrm{C}-\mathrm{H}^{\cdots \cdots} \mathrm{O} \mathrm{H}-\mathrm{Bonding}$ between Phe and Glu Side Chains in $\alpha$-Helical Peptides. Biophys. Chem., 2002, 101-102, 267-279.

(40) Singh, S. K.; Babu, M. M.; Balaram, P. Registering $\alpha$-Helices and B-Strands Using Backbone C-H...O Interactions. Proteins Struct. Func. Genetics, 2003, 51, 167-171.

(41) Ash, E. L.; Sudmeier, J. L.; Day, R. M.; Vincent, M.; Torchilin, E. V.; Haddad, K. C.; Bradshaw, E. M.; Sanford, D. G.; Bachovchin, W. W. Unusual ${ }^{1} \mathrm{~h}$ Nmr Chemical Shifts Support (His) $\mathrm{C}^{\varepsilon 1}-\mathrm{H}^{\cdots \cdots} \mathrm{O}=\mathrm{C}$ H-Bond: Proposal for Reaction-Driven Ring Flip Mechanism in Serine Protease Catalysis. Proc. Nat. Acad. Sci., USA, 2000, 97, 10371-10376.

(42) Nanda, V.; Schmiedekamp, A. Are Aromatic Carbon Donor Hydrogen Bonds Linear in Proteins? Proteins Struct. Func. Genetics, 2008, 70, 489-497.

(43) Derewenda, Z. S.; Derewenda, U.; Kobos, P. M. (His) $\mathrm{C}^{\varepsilon}-\mathrm{H}^{\cdots \cdots} \mathrm{O}=\mathrm{C}<\mathrm{Hydrogen}$ Bond in the Active Sites of Serine Hydrolases. J. Mol. Biol., 1994, 241, 83-93.

(44) Del Rizzo, P. A.; Couture, J.-F.; Dirk, L. M. A.; Strunk, B. S.; Roiko, M. S.; Brunzelle, J. S.; Houtz, R. L.; Trievel, R. C. Set7/9 Catalytic Mutants Reveal the Role of Active Site Water Molecules in Lysine Multiple Methylation. J. Biol. Chem., 2010, 285, 3184931858.

(45) Seiler, P.; Weisman, G. R.; Glendening, E. D.; Weinhold, F.; Johnson, V. B.; Dunitz, J. D. Observation of an Eclipsed $\mathrm{C}_{\mathrm{sp}} 3-\mathrm{Ch}_{3}$ Bond in a Tricyclic Orthoamide; Experimental and Theoretical Evidence for $\mathrm{C}-\mathrm{H}^{\cdots} \mathrm{O}$ Hydrogen Bonds. Angew. Chem., Int. Ed. Engl., 1987, 26, 1175-1177.

(46) Paton, R. S.; Goodman, J. M. Understanding the Origins of Remote Asymmetric Induction in the Boron Aldol Reactions of B-Alkoxy Methyl Ketones. Org. Lett., 2006, 8, 4299-4302.

(47) Samanta, A. K.; Pandey, P.; Bandyopadhyay, B.; Chakraborty, T. Cooperative Strengthening of an Intramolecular $\mathrm{O}-\mathrm{H} \cdots \mathrm{O}$ Hydrogen Bond by a Weak $\mathrm{C}-\mathrm{H} \cdots \mathrm{O}$ Counterpart: Matrix-Isolation Infrared Spectroscopy and Quantum Chemical Studies on 3-Methyl-1,2-Cyclohexanedione. J. Phys. Chem. A, 2010, 114, 1650-1656.

(48) Sonoda, Y.; Goto, M.; Ikeda, T.; Shimoi, Y.; Hayashi, S.; Yamawaki, H.; Kanesato, M. Ntermolecular Ch'”O Hydrogen Bonds in Formyl-Substituted Diphenylhexatriene, a [2 + 2] Photoreactive Organic Solid: Crystal Structure and Ir, Nmr Spectroscopic Evidence. J. Mol. Struct., 2011, 1006, 366-374.

(49) Bandyopadhyay, B.; Pandey, P.; Banerjee, P.; Samanta, A. K.; Chakraborty, T. Ch‥O Interaction Lowers Hydrogen Transfer Barrier to Keto-Enol Tautomerization of BCyclohexanedione: Combined Infrared Spectroscopic and Electronic Structure Calculation Study. J. Phys. Chem. A, 2012, 116, 3836-3845.

(50) Kothari, A.; Qureshi, M. K. N.; Beck, E. M.; Smith, M. D. Bend-Ribbon Forming $\Gamma$ Peptides. Chem. Commun., 2007, 2814-2816.

(51) Qureshi, M. K. N.; Smith, M. D. Parallel Sheet Structure in Cyclopropane $\Gamma$-Peptides Stabilized by $\mathrm{C}-\mathrm{H}^{\prime \cdots} \mathrm{O}$ Hydrogen Bonds. Chem. Commun., 2006, 5006-5008.

(52) Jones, C. R.; Qureshi, M. K. N.; Truscott, F. R.; Hsu, S.-T. D.; Morrison, A. J.; Smith, M. D. A Nonpeptidic Reverse Turn That Promotes Parallel Sheet Structure Stabilized by C- 
H“'O Hydrogen Bonds in a Cyclopropane Г-Peptide. Angew. Chem. Int. Ed., 2008, 47, 7099-7102.

(53) Jones, C. R.; Pantos, G. D.; Morrison, A. J.; Smith, M. D. Plagiarizing Proteins: Enhancing Efficiency in Asymmetric Hydrogen-Bonding Catalysis through Positive Cooperativity. Angew. Chem. Int. Ed., 2009, 48, 7391-7394.

(54) Jones, C. R.; Baruah, P. K.; Thompson, A. L.; Scheiner, S.; Smith, M. D. Can a C-H ․O Interaction Be a Determinant of Conformation. J. Am. Chem. Soc., 2012, 134, 1206412071.

(55) Scheiner, S. Contributions of $\mathrm{Nh} \cdot \mathrm{O}$ and $\mathrm{Ch} \cdot \cdot \mathrm{O} \mathrm{H}$-Bonds to the Stability of B-Sheets in Proteins. J. Phys. Chem. B, 2006, 110, 18670-18679.

(56) Vener, M. V.; Egorova, A. N.; Fomin, D. P.; Tsirelson, V. G. Qtaim Study of the ClosedShell Interactions in Peptide Secondary Structures: A Cluster Treatment of Oligo- and Polyalanines. Chem. Phys. Lett., 2007, 440, 279-285.

(57) Parthasarathi, R.; Raman, S. S.; Subramanian, V.; Ramasami, T. Bader's Electron Density Analysis of Hydrogen Bonding in Secondary Structural Elements of Proteins. J. Phys. Chem. A, 2007, 111, 7141-7148.

(58) Vener, M. V.; Egorova, A. N.; Fomin, D. P.; Tsirel'son, V. G. A Quantum-Topological Analysis of Noncovalent Interactions in Secondary Polyalanine Structures. Russ. J. Phys. Chem. B., 2009, 3, 541-547.

(59) Guo, H.; Gorin, A.; Guo, H. A Peptide-Linkage Deletion Procedure for Estimate of Energetic Contributions of Individual Peptide Groups in a Complex Environment: Application to Parallel B-Sheets. Interdiscip. Sci. Comput. Life Sci., 2009, 1, 12-20.

(60) Frisch, M. J.; Trucks, G. W.; Schlegel, H. B.; Scuseria, G. E.; Robb, M. A.; Cheeseman, J. R.; Scalmani, G.; Barone, V.; Mennucci, B.; Petersson, G. A. et al, Gaussian 09. Revision B.01 ed. 2009

(61) Zhao, Y.; Truhlar, D. G. Comparative Dft Study of Van Der Waals Complexes: Rare-Gas Dimers, Alkaline-Earth Dimers, Zinc Dimer, and Zinc-Rare-Gas Dimers. J. Phys. Chem. A, 2006, 110, 5121-5129.

(62) Molnar, L. F.; He, X.; Wang, B.; Merz, K. M. Further Analysis and Comparative Study of Intermolecular Interactions Using Dimers from the S22 Database. J. Chem. Phys., 2009, 131, 065102.

(63) Vincent, M. A.; Hillier, I. H. The Structure and Interaction Energies of the Weak Complexes of $\mathrm{Chclf}_{2}$ and $\mathrm{Chf}_{3}$ with Hcch: A Test of Denstiy Functional Theory Methods. Phys. Chem. Chem. Phys., 2011, 13, 4388-4392.

(64) Biller, M. J.; Mecozzi, S. A High Level Computational Study of the $\mathrm{Ch}_{4} / \mathrm{Cf}_{4}$ Dimer: How Does It Compare with the $\mathrm{Ch}_{4} / \mathrm{Ch}_{4}$ and $\mathrm{Cf}_{4} / \mathrm{Cf}_{4}$ Dimers? Mol. Phys., 2012, 110, 377-387.

(65) Podeszwa, R.; Szalewicz, K. Density Functional Theory Overcomes the Failure of Predicting Intermolecular Interaction Energies. J. Chem. Phys., 2012, 136, 161102.

(66) Forni, A.; Pieraccini, S.; Rendine, S.; Gabas, F.; Sironi, M. Halogen-Bonding Interactions with П Systems: Ccsd(T), Mp2, and Dft Calculations. ChemPhysChem., 2012, 13, 42244234.

(67) Kozuch, S.; Martin, J. M. L. Halogen Bonds: Benchmarks and Theoretical Analysis. J. Chem. Theory Comput., 2013, 9, 1918-1931.

(68) Kerdawy, A. E.; Murray, J. S.; Politzer, P.; Bleiziffer, P.; Heßelmann, A.; Görling, A.; Clark, T. Directional Noncovalent Interactions: Repulsion and Dispersion. J. Chem. Theory Comput., 2013, 9, 2264-2275. 
(69) Remya, K.; Suresh, C. H. Which Density Functional Is Close to Ccsd Accuracy to Describe Geometry and Interaction Energy of Small Non-Covalent Dimers? A Benchmark Study Using Gaussian09. J. Comput. Chem., 2013, 34, 1341-1353.

(70) Doemer, M.; Tavernelli, I.; Rothlisberger, U. Intricacies of Describing Weak Interactions Involving Halogen Atoms within Density Functional Theory. J. Chem. Theory Comput., 2013, 17, 955-964.

(71) Rosokha, S. V.; Stern, C. L.; Ritzert, J. T. Experimental and Computational Probes of the Nature of Halogen Bonding: Complexes of Bromine-Containing Molecules with Bromide Anions. Chem. Eur. J., 2013, 19, 8774-8788.

(72) Reed, A. E.; Weinhold, F.; Curtiss, L. A.; Pochatko, D. J. Natural Bond Orbital Analysis of Molecular Interactions: Theoretical Studies of Binary Complexes of $\mathrm{Hf}, \mathrm{H}_{2} \mathrm{O}, \mathrm{Nh}_{3}, \mathrm{~N}_{2}$, $\mathrm{O}_{2}, \mathrm{~F}_{2}, \mathrm{Co}$ and $\mathrm{Co}_{2}$ with $\mathrm{Hf}, \mathrm{H}_{2} \mathrm{O}$, and $\mathrm{Nh}_{3}$. J. Chem. Phys., 1986, 84, 5687-5705.

(73) Reed, A. E.; Curtiss, L. A.; Weinhold, F. Intermolecular Interactions from a Natural Bond Orbital, Donor-Acceptor Viewpoint. Chem. Rev., 1988, 88, 899-926.

(74) Marom, N.; Tkatchenko, A.; Rossi, M.; Gobre, V. V.; Hod, O.; Scheffler, M.; Kronik, L. Dispersion Interactions with Density-Functional Theory: Benchmarking Semiempirical and Interatomic Pairwise Corrected Density Functionals. J. Chem. Theory Comput., 2011, 7, 3944-3951.

(75) Wheeler, S. E.; Houk, K. N. Integration Grid Errors for Meta-Gga-Predicted Reaction Energies: Origin of Grid Errors for the M06 Suite of Functionals. J. Chem. Theory Comput., 2010, 6, 395-404.

(76) Grimme, S. Semiempirical Gga-Type Density Functional Constructed with a Long-Range Dispersion Correction. J. Comput. Chem., 2007, 27, 1787-1799.

(77) Chai, J.-D.; Head-Gordon, M. Systematic Optimization of Long-Range Corrected Hybrid Density Functionals. J. Chem. Phys., 2008, 128, 084106.

(78) Majumder, M.; Mishra, B. K.; Sathyamurthy, N. Ch“” $\Pi$ and $\Pi \cdots \cdots \Pi$ Interaction in BenzeneAcetylene Clusters. Chem. Phys., 2013, 557, 59-65.

(79) Wu, W.; Lu, Y.; Liu, Y.; Li, H.; Peng, C.; Liu, H.; Zhu, W. Weak Energetic Effects between X-П and X-N Halogen Bonds: Csd Search and Theoretical Study. Chem. Phys. Lett., 2013, 582, 49-55. 


\section{FIGURE CAPTIONS}

Fig 1. Structures of molecule I, with lower peptide group turned so as to present its CO group toward the upper in a, and its $\mathrm{NH}$ group turned in this direction in b. Important atoms are labeled, as are the dihedral angles discussed in the text.

Fig 2. Energy as a function of dihedral angle $\psi$ for the simple dipeptide (broken curve) and full molecule I (solid curve). Red and blue colors indicate respectively whether the lower peptide is oriented with $\mathrm{CO}$ or NH group pointing up toward the upper dipeptide. Zero of energy is taken as the lowest value in the profile of each.

Fig. 3. Structures of minima on the potential energy surface of the dipeptide segment $\mathrm{NH}_{2} \mathrm{COCH}_{2} \mathrm{NHCOCH}_{3}$, indicating internal H-bond.

Fig 4. Energy as a function of dihedral angle $\psi$ for a) simple dipeptide and b) full molecule I with lower peptide held with $\mathrm{CO}$ group up facing the dipeptide. The interaction energy computed for the upper and lower units, in the absence of intervening phenyl and other groups, is shown in c. The sum of the latter interaction energy in $\mathrm{c}$ and the intrinsic energy of the dipeptide in a is depicted in $\mathrm{d}$. For $\mathrm{a}, \mathrm{b}$, and $\mathrm{d}$, the value of zero is assigned to the lowest energy; quantities shown in c represent absolute values.

Fig 5. Energy as a function of dihedral angle $\psi$ for a) simple dipeptide and b) full molecule I with lower peptide held with $\mathrm{NH}$ group up facing the dipeptide. $\mathrm{c}$ shows the interaction energy between the upper and lower units, in the absence of intervening phenyl and other groups, and d represents the sum of $\mathrm{c}$ and a.

Fig. 6 Structures of selected geometries of molecule I. Selected interatomic distances are in $\AA$. 
TOC GRAPHIC:

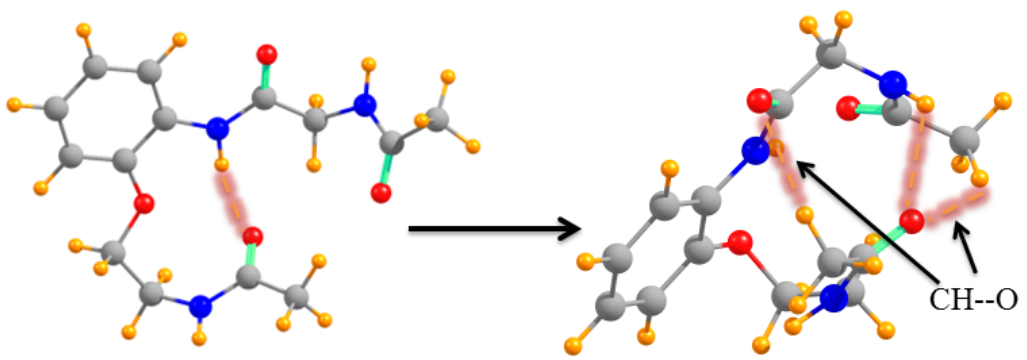

